Household surveys

\section{Injury questions on household surveys from around the world}

\author{
M Heinen, K S McGee, M Warner
}

Household surveys provide useful information on injury and associated risk factors

$\mathrm{H}$ ousehold surveys are used around the world to gather information on many health related topics including non-fatal injuries. Household surveys can produce population based estimates of injuries that may stand on their own or may supplement surveillance systems tied to medical care. They are not subject to the same biases as medical records reviews. For example, household surveys can obtain a wealth of detail on the circumstances of the injury, which are often not in the medical record, and they can capture injuries that were not medically treated. They are, however, subject to different types of bias such as non-response and recall bias.

National estimates of non-fatal injuries can be derived based on the responses to specific questions about injuries. Estimates are often compared across countries despite the fact that the injury screening questions and inclusion criteria vary between countries. The estimate-whether it is of injured persons or injury episodes or injury related conditions-is often based on the response to a single screening question on injury; therefore, the way this question is asked is critical. Based on the screening question, the respondent needs to understand the definition of "injury", remember if they had an injury during the specified recall period, and decide whether to accurately report the event.

Since there is currently no standard or recommended set of injury related questions or inclusion criteria for questions to be asked in a household survey, the International Collaborative Effort on Injury Statistics (Injury ICE) ${ }^{1}$ set out to learn how some countries are asking questions to determine the burden of non-fatal injuries. This brief report presents an overview of the compiled information. The detailed results are available on the ICE on Injury Statistics website (http://www.cdc.gov/ nchs/advice) along with the complete questions and response categories for all the elements reviewed in the surveys.

\section{METHODS}

A convenience sample of 14 household surveys from 14 different countries was reviewed. A list of references used to glean the information about each survey is provided (see box 1). A collaborator for each country assisted and offered country specific knowledge. The collaborators listed before the reference section verified the accuracy of the information for their country. For the remaining countries for which a collaborator could not be identified, we relied on information in publications or the internet that was reviewed. In some cases surveys were translated to English by the contact. However, in country gesetz.shtml Stockholm: Karolinska Institute, 2000. index.htm survey01/nfa/nfa01.htm

- Denmark: www.niph.dk

- France: www.cnamsts.fr

- Germany: www.baua.de

- Israel: www.cbs.gov.il avance_resultados.htm urban Uganda. Inj Prev 2001;7:46-50. other countries (for example, Ghana, Uganda, and Pakistan) English language versions as well as versions in the local language or languages are available.

The results from this analysis are available on the ICE on Injury Statistics website (http://www.cdc.gov/ nchs/advice) and also on the journal website (http:/www.injuryprevention. com/supplemental). Table 1 presents selected survey elements (for example, population/setting) and methodologies (for example, recall period and severity threshold) listed by country. Table 2 presents the introduction to the injury questions and the screening question. Table 3 compares the minimum data elements (for example, activity and nature of injury) on injury collected by each country.

\section{SUMMARY}

Many countries have household based injury surveys, but the survey methodology and questions vary greatly between countries. Some surveys allowed self and proxy reporting of injuries while others allowed only self reporting of injuries (table 1). Some surveys included only unintentional injuries while others included all injuries

Box 1: Websites and other references used for each survey listed by

- Australia: www.abs.gov.au (click on themes and then health)

- Austria: http://www.statistik.at/fachbereich_03/mikrozensus

- Bangladesh: Fazlur Rahman AKM. A model for injury surveillance at the local level in Bangladesh: implications for low-income countries.

- Canada: http://www.statcan.ca/english/concepts/health/cycle2_1/

- England: hitp://www.official-documents.co.uk/document/deps/doh/

- Ghana: Mock CN, Abantanga F, Cummings P, et al. Incidence and outcome of injury in Ghana: a community-based survey. Bulletin of the World Health Organization 1999;77:955-64.

- Pakistan: Ghaffar A. National Injury Survey of Pakistan, 1997-1999. Islamabad: National Injury Research Centre, Health Service Academy, Ministry of Health, Government of Pakistan, 2000.

- Spain: http://www.msc.es/salud/epidemiologia/ies/encuesta2001/

- Uganda: Kobusingye O, Guwatudde D, Lett R. Injury patterns in rural and

- United States: http://www.codc.gov/nchs/nhis.htm 


\section{Key points}

- Household surveys can produce population based estimates of injuries that may stand on their own or may supplement surveillance systems tied to medical care.

- International Collaborative Effort on Injury Statistics (Injury ICE) presents how some countries are asking questions to determine the burden of nonfatal injuries.

- Many countries have household based injury surveys, but the survey methodology and questions vary greatly between countries.

- This paper provides a range of options when developing a new survey or redesigning a current survey aimed at gathering population level data on injuries.

regardless of intent. The time periods in which the respondent was asked to recall the injury event in the surveys reviewed ranged from 15 days to 12 months. The severity threshold for inclusion in the survey was injuries "requiring medical attention" in some countries while others limited inclusion to those injuries "causing some limitation in activity". The severity of the injuries included affects both the quantity of injuries captured and the quality of the data. Some countries analyzed the most severe injuries occurring during the reference period, others used the most recent, and some analyzed all injuries. Additionally, some of the surveys, particularly those from low and middle income countries, collect information on fatal injuries suffered by members of the household within a specified recall period. Collecting data on fatal injuries is particularly important in countries where there is no death registration system or where the quality of death registration is poor. Sampling design and the use of sample weights are also important factors related to prevalence estimates based on sample data. We did ask about sample design and found that it varied from the use of simple random samples to multistage probability samples. We did not specifically ask about the application of sample weights.

Table 2 shows the variation among countries in the placement of the text defining injury for the respondent, the implicit inclusion criteria given to the respondent, and the number and choice of example injuries. Both the introduction to the section and screening question(s) need to be considered when assessing the comparability among countries. In many countries important information about the definition of injury is contained in the introduction to the injury section, and so the definition of injury used for the survey should be included in any comparison. Table 3 illustrates that the amount of detail collected on each injury varied by country with some not including activity, location, or intent of the injury.

\section{COMMENT}

The tables show the variety of ways the populations in different countries are surveyed about injury. Currently, there is not a recommended standard basic injury module that applies to all countries and this may be appropriate, as some of the variation in surveys is needed based on many factors such as cultural differences, socioeconomic differences, timing of the survey (for example, continuous, annual, or biannual), and scope of the survey (for example, regional or national). By presenting alternative approaches, this paper provides a range of options when developing a new survey or redesigning a current survey.

In an attempt to provide guidance on conducting community based (not necessarily national) household surveys, the World Health Organization (WHO), in collaboration with an international group of experts, developed a document entitled, Guidelines for Conducting Community Surveys on Injuries and Violence. ${ }^{2}$ These guidelines provide a standardized methodology for designing and conducting community based household surveys and promote the use of a standard set of variables to collect the data. The guidelines are intended for injury prevention practitioners in low and middle income countries and provide guidance on conducting surveys that are local as opposed to national in scope. The recommendations made in the guidelines are based on household surveys conducted in many countries and some of the surveys are included in this paper. However, the majority of the household surveys in this paper are from high income countries and are national in scope. Another set of guidelines for conducting injury surveillance, the Injury Surveillance Guidelines, ${ }^{3}$ focused on hospital based injury surveillance in less resourced environments and has been successfully implemented in numerous countries. Many definitions between the two guidelines are similar and designed to provide consistency with other international initiatives.

The International Classification of External Causes of Injury (ICECI ${ }^{4}$ is also a resource to promote the international standardization of injury data. The aim of the ICECI is to assist researchers in defining the domain of injuries they are studying, answer questions on the circumstances of the injuries, and provide more detailed information about specific injury categories. In October of 2003, the WHO adopted the ICECI as a related classification into the family of classifications. Some of the response categories in the Australian and United States household surveys are based on previous versions of the ICECI. More detail and documentation on the ICECI can be found at www.iceci.org.

Household surveys can provide useful information on the burden of injury and associated risk factors. We hope the information provided here will stimulate further discussion on the question wording and other methodological issues related to household injury surveys and prompt more work in the area.

\section{ACKNOWLEDGEMENTS}

We are grateful for the careful review of details for their countries given by the following collaborators: James Harrison (Australia); Olive Kobusingye (Uganda); Susan Mackenzie (Canada); Charles Mock (Ghana); Mathilde Sector (Austria, France, Germany, and Denmark); Maria SeguiGomez (Spain); Pnina Zadka (Israel); and James Dahlhamer (United States). We would also like to acknowledge the International Collaborative Effort (ICE) on Injury Statistics for providing the initial forum for conducting this research.

Injury Prevention 2004;10:327-329.

doi: 10.1136/ip.2004.005991

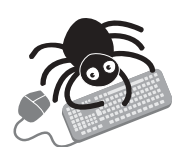

Tables 1-3 appear on http://www.

injuryprevention.com/ supplemental

\section{Authors' affiliations}

M Heinen, M Warner, Office of Analysis and Epidemiology, National Center for Health Statistics, Centers for Disease Control and Prevention, Hyattsville, Maryland, USA K S McGee, Department of Injuries and Violence Prevention, World Health Organization, Geneva, Switzerland

Correspondence to: Ms Kara S McGee, University of North Carolina Injury Prevention Research Center, 137 East Franklin Street, CB\# 7505, Chapel Hill, NC 27599-7505, USA; ksmcgee@email.unc.edu 


\section{SPECIAL REPORT}

\section{REFERENCES}

1 Centers for Disease Control and Prevention, National Center for Health Statistics. International collaborative effort (ICE) on injury statistics. Hyattsville, MD: NCHS lavailable at: http://www.cdc.gov/nchs/advice.htm).
2 Sethi D, Habibula S, McGee K, et al. Guidelines for conducting community surveys on injuries and violence. Geneva: World Health Organization (in press).

3 Holder $\mathrm{Y}$, Peden $M$, Krug $E$, et al, eds. Injury surveillance guidelines. Geneva: World Health Organization, 2001.
4 WHO Working Group on Injury Surveillance Methods. International classification of external causes of injuries (ICECI): data dictionary, version 1.1a. Adelaide: Consumer Safety Institute, Amsterdam and AlHW National Injury Surveillance Unit, 2003

\section{Calendar}

RoSPA Road Safety Congress

28 February-2 March 2005, Brighton, UK. The theme of the 70th Road Safety Congress is "Driving Deaths Down". The organisers pose the questions "Have the 'easy wins' been achieved? Will further reductions be much harder to achieve, especially for drivers, car occupants and motorcyclists?" The review of the Road Safety Strategy highlights the need for further action in key areas, and the congress will explore what more can be done in these areas to influence driver and rider behaviour to prevent crashes from happening in the first place. Visit the road safety section of the www.rospa.com for more information.

19th International Technical Conference on the Enhanced Safety of Vehicles Conference (ESV)

6-9 June 2005, Washington, DC, USA. Visit www-esv2005.nhtsa.dot.gov.

14th International Safe Communities Conference

13-15 June 2005, Bergen, Norway. Further information: www.safebergen.com.

1st World Congress on Sports Injury Prevention

23-25 June 2005, Oslo, Norway. The 1st World Congress on Sports Injury Prevention will provide an overview of how injuries in sports can be effectively prevented. The second announcement and programme are now available at the conference website www.ostrc.no/ congress2005.

3rd New Zealand Injury Prevention Conference

2-4 November 2005, Wellington, New Zealand. "Living and playing safely in Aotearoa New Zealand" is the theme of this meeting. Visit www.ipn.org.nz for more information.

8th World Conference on Injury Prevention and Safety Promotion 19-22 March 2006, Johannesburg, South Africa. Further information and key dates: www.safety2006.info. 